\title{
PENGARUH VARIASI KEDALAMAN POTONG DAN KECEPATAN PUTAR MESIN BUBUT TERHADAP KEKASARAN PERMUKAAN BENDA KERJA HASIL PEMBUBUTAN RATA PADA BAHAN BAJA ST 37
}

\author{
Oleh \\ K Sutrisna ${ }^{1}$ I N Pasek Nugraha ${ }^{2}$ K Rihendra Dantes ${ }^{3}$ \\ 1,2,3 Jurusan Pendidikan Teknik Mesin \\ Universitas Pendidikan Ganesha
}

E-mail: deksutrisna@gmail.com ${ }^{1}$, paseknugraha@undiksha.ac.id², rihendra79@gmail.com³.

\begin{abstract}
ABSTRAK
Penelitian ini bertujuan untuk mengetahui pengaruh variasi kedalaman potong dan kecepatan putar mesin bubut terhadap kekasaran permukaan benda kerja hasil pembubutan rata pada bahan baja ST 37. Penelitian ini merupakan penelitian metode eksperimen dengan variabel terikat yaitu kekasaran permukaan, dan variabel bebas yaitu kedalaman potong dan kecepatan putar. Dari hasil uji analisis statistik varian dua jalur dimana kedalaman potong menunjukan bahwa nilai $F$ hitung sebesar 26,860 lebih besar dari $F$ tabel $=4,11$ $\left(F_{h}>F_{t}\right)$. Ini berarti bahwa $H_{1}$ diterima yang menyatakan bahwa terdapat perbedaan yang signifikan kekasaran permukaan bahan baja st 37 antara kedalaman potong $0,4 \mathrm{~mm}$ dibandingkan dengan kedalaman potong $0,8 \mathrm{~mm}$. Pada kecepatan putar diproleh nilai $F$ hitung sebesar 4,565 lebih besar dari $F$ tabel 4,11 $\left(\mathrm{F}_{\mathrm{h}}>\mathrm{F}_{\mathrm{t}}\right)$. Ini berarti bahwa $H_{1}$ diterima yang menyatakan bahwa terdapat perbedaan yang signifikan kekasaran permukaan bahan baja st 37 antara kecepatan putar $330 \mathrm{rpm}$ dibandingkan dengan kecepatan putar 490 rpm, dan hasil uji analisis varian dua jalur antara kedalaman potong dengan kecepatan putar menunjukan nilai $F$ hitung sebesar 73.229 lebih besar dari $F$ tabel $4.11\left(\mathrm{~F}_{\mathrm{h}}>\mathrm{F}_{\mathrm{t}}\right)$. Ini berarti bahwa $H_{1}$ diterima yang menyatakan terdapat interaksi yang signifikan kekasaran permukaan bahan baja st 37 antara kedalaman potong $0,4 \mathrm{~mm}$ dan kedalaman potong $0,8 \mathrm{~mm}$ dibandingkan dengan kecepatan putar 330 RPM dan kecepatan putar 490 rpm.
\end{abstract}

Bedasarkan dari hasil yang telah didapat bahwa kedalaman potong $0,4 \mathrm{~mm}$ dengan kecepatan $490 \mathrm{rpm}$ mengasilkan hasil pembubutan yang lebih halus dibandingkan dengan kedalaman potong $0,8 \mathrm{~mm}$ dengan kecepatan $330 \mathrm{rpm}$, kedalaman potong $0,4 \mathrm{~mm}$ dengan kecepatan $330 \mathrm{rpm}$, dan kedalaman potong $0,8 \mathrm{~mm}$ dengan kecepatan $490 \mathrm{rpm}$.

Kata kunci :pengaruh kedalaman potong, pengaruh kecepatan putar, kekasaran permukaan.

\section{ABSTRACT}

The aims of this study is to determine the effect of variation of depth cutting and lathe speed rotation on roughness surface of the flat scaling work-piece on steel materials ST 37. This is an experimental method research with the dependent variable that is roughness surface, and the independent variables are depth cutting and rotational speed.

From the test results of statistical analysis of two-lane variants where the depth of cut shows that the value of $F$ arithmetic of 26.860 is greater than $F$ table $=$ 
4.11 (Fh> Ft). This means that $H_{1}$ is accepted which states that there is a significant difference in roughness surface steel materials st 37 between depths cutting of $0.4 \mathrm{~mm}$ compared to a depth cutting of $0.8 \mathrm{~mm}$. At the rotational speed, the result $F$ calculated value of 4.565 bigger than $F$ table $4.11(\mathrm{Fh}>\mathrm{Ft}$ ). This means that $H_{1}$ is accepted which states that there is a significant difference in roughness surface material steel ST 37 between rotational speed $330 \mathrm{rpm}$ compared to $490 \mathrm{rpm}$ rotational speed, and the result of the analysis of the twolane variance between cutting depth and rotational speed shows $F$ calculated value of 73,229 more Large of $\mathrm{F}$ table $4.11(\mathrm{Fh}>\mathrm{Ft})$. This means that $H_{1}$ is accepted which states there is significant interaction of surface roughness of st 37 steel material between $0.4 \mathrm{~mm}$ cutting depth and $0.8 \mathrm{~mm}$ cutting depth compared with rotational speed 330 RPM and 490 rpm rotational speed

Based on the results, it can be said that $0.4 \mathrm{~mm}$ depth cutting at a speed of 490 rpm yielded a finer grinding result compared to $0.8 \mathrm{~mm}$ cutting depth at 330 rpm, $0.4 \mathrm{~mm}$ cutting depth at $330 \mathrm{rpm}$, and cutting depth $0.8 \mathrm{~mm}$ with a speed of $490 \mathrm{rpm}$

Keywords: the effect of depth cutting, the effect of speed rotation, roughness surface.

\section{PENDAHULUAN}

Perkembangan teknologi yang semakin canggih dan modern khususnya dibidang industri baik mesin perkakas, mesin pembangkit, dan metalurgi berperan penting dalam dunia industri. Seperti halnya untuk mesin perkakas yang digunakan dalam proses pemesinan meliputi mesin bubut, mesin frais, mesin bor, mesin sekrap, gerinda, dan lain-lain. Proses bubut merupakan proses pembentukan material dengan membuang sebagian material dalam bentuk geram akibat adanya gerak relatif pahat terhadap benda kerja, dimana benda kerja diputar pada spindel dan pahat dihantarkan ke benda kerja secara translasi (Kalpakjian, 2001).

Kualitas hasil pembubutan terutama permukaan dipengaruhi oleh tiga parameter yaitu kecepatan putar spindel (speed), gerak makan (feed), dan kedalaman potong (depth of cut). Faktor yang lain seperti bahan benda kerja dan jenis pahat sebenarnya memiliki pengaruh yang cukup besar, tetapi tiga parameter di atas adalah bagian yang dapat diatur oleh operator secara langsung pada mesin bubut.

$\begin{array}{ll}\text { Bimbing Atedi dan Djoko Agustono } \\ \text { (2005) } & \begin{array}{l}\text { Anyatakan } \\ \text { bahwa" }\end{array}\end{array}$ Karakteristik suatu kekasaran permukaan memegang perana penting dalam perancangan komponen mesin. Hal tersebut perlu dinyatakan dengan jelas misalnya dalam kaitannya dengan gesekan, keausan, pelumasan, ketahanan kelelahan, perekatan dua atau lebih komponen-komponen mesin". Salah satu syarat yang mempengaruhi kekasaran permukaan pada pembubutan adalah kedalaman potong dan kecepatan putar, dengan menggunakan variasi kedalaman potong dan kecepatan putar mesin bubut yang sudah ditentukan dapat mengetahui perbedaan hasil kekasaran permukaan pada bahan baja St.37.

Pada proses pembubutan

kekasaran dari hasil pekerjaan merupakan hal yang sangat penting. Kualitas pembubutan logam sangat dipengaruhi oleh jenis pahat yang digunakan seperti misalnya pahat bubut High Speed steel (HSS) dan karbida. Pahat HSS merupakan baja karbon tinggi yang mengalami proses perlakuan panas (heat treatment) sehingga kekerasan menjadi cukup tinggi dan tahan terhadap temperatur tinggi tanpa menjadi lunak (annealed) (Rochim, 1993). Pahat bubut HSS merupakan paduan dari 0,75\%-1,5\% Carbon (C), 4\% 4,5\% Chromium (Cr), 10\%$20 \%$ Tungsten (W) dan Molybdenum (Mo), $5 \%$ lebih Vanadium (V), dan Cobalt (Co) lebih dari $12 \%$ (Childs, dkk, 2000)

Jurnal Pendidikan Teknik Mesin Undiksha | 2 


\section{KEKASARAN PERMUKAAN}

Kekasaran permukaan adalah penyimpangan rata-rata aritmetik dari garis rata-rata permukaan. Dalam dunia indistri, permukaan benda kerja memiliki nilai

\section{PENGERTIAN MESIN BUBUT}

Proses bubut adalah proses pemesinan untuk menghasilkan bagian bagian mesin berbentuk silindris yang dikerjakan dengan

menggunakan mesin bubut. Prinsip dasarnya dapat didefinisikan sebagai proses pemesinan permukaan luar benda silindris atau bubut rata:

1. Dengan benda kerja yang berputar

2. Dengan satu pahat bermata potong tunggal (with a single-pointcutting tool) kekasaran permukaan yang berbeda, sesuai dengan kebutuhan dari penggunaan alat tersebut dan untuk alat uji kekasaran permukaan mengunakan surface tester SJ 210.

3. Dengan gerakan pahat sejajar terhadap sumbu benda kerja pada jarak tertentu

\section{PROSEDUR PENELITIAN}

Prosedur penelitian adalah serangkaian kegiatan yang dilaksanakan oleh seorang peneliti secara teratur dan sistematis untuk mencapai tujuan-tujuan penelitian. Dalam penelitian ini dapat dijelaskan secara sederhana oleh diagram proses alur penelitian adalah sebagai berikut:

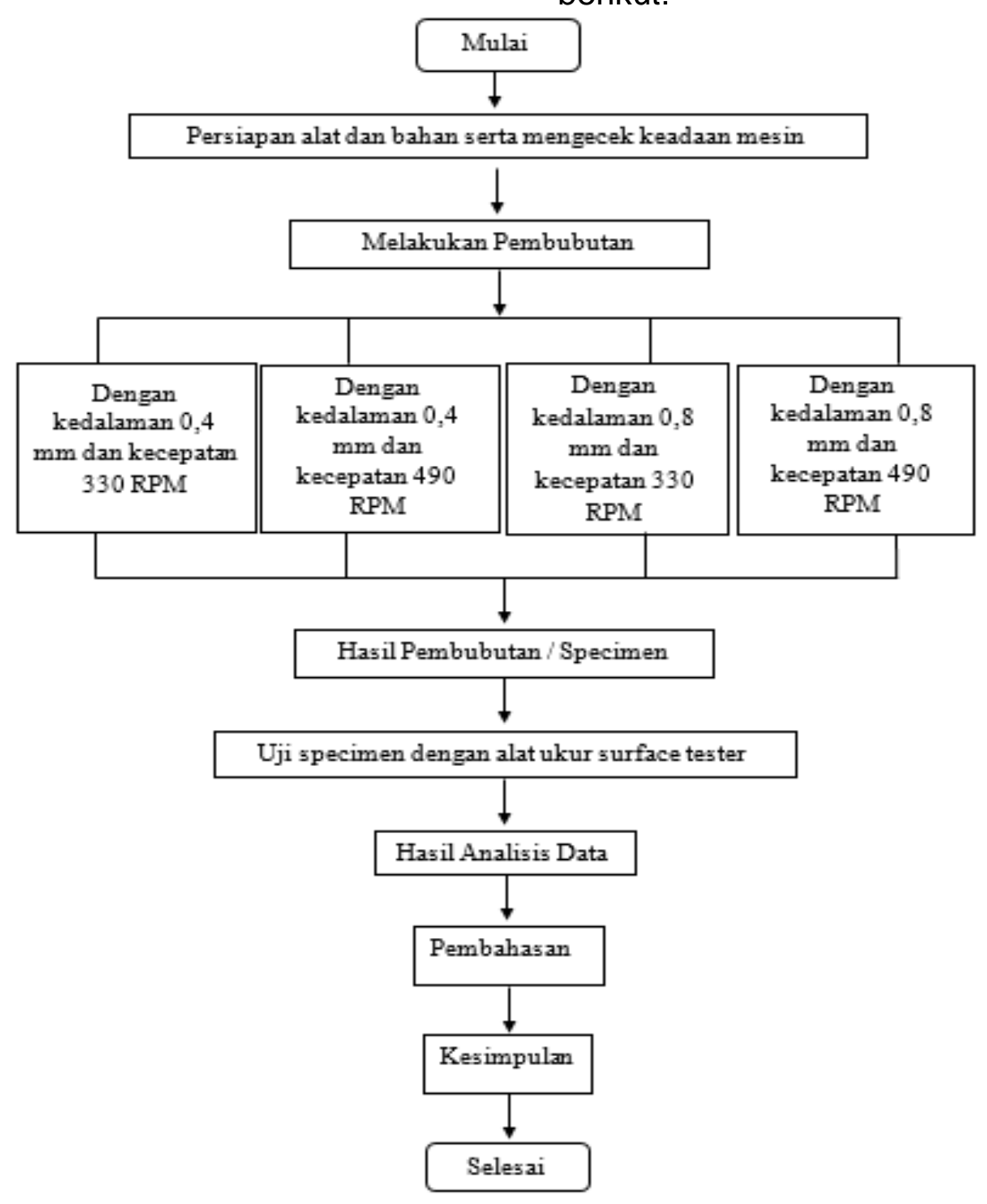

Gambar 1 Diagram Alir Penelitian 


\section{PERSIAPAN BAHAN DAN ALAT}

Sebelum dilakukan proses pembubutan dilakukan persiapan beberapa hal seperti persiapan bahan dan alat yang digunakan. Adapun dalam penelitian ini bahan dan alat yang perlu disiapkan antara lain :

1. Benda Kerja

Material benda kerja yang digunakan pada penelitian ini adalah material Baja St.37. Material ini memiliki dimensi diameter $22 \mathrm{~mm}$ dengan panjang $30 \mathrm{~mm}$

Komposisi bahan Baja St 37 (baja karbon rendah)

C : 0,22\% Mn : 0,30-0,65 \% SI : 0,30 \% P : $0,045 \%$ S : $0,045 \%$

Sifat mekanik :

Kekuatan luluh Min : $215 \mathrm{Mpa}$

\section{PEMBAHASAN DESKRIPSI DATA}

Deskripsi data dalam penelitian ini akan memaparkan mengenai jumlah subyek (N), skor minimum, maksimum, skor rata-rata $(\mathrm{M})$, standar deviasi (SD) dan
Kekuatan panjang Min : $375 \mathrm{Mpa}$

Pemanjangan Min : $22 \%$

2. Pahat HSS

Pahat HSS yang digunakan adalah pahat HSS ALLWIN ukuran 1/2" $x$ 1/2"x 6"'

3. Mesin Bubut Manual

Mesin bubut manual yang digunakan pada penelitian ini adalah mesin bubut yang terdapat di lab Ganesha Manufacture 2 Pendidikan Teknik Mesin, Fakultas Teknik dan Kejuruan, UNDIKSHA. Adapun spesifikasinya adalah sebagai berikut:

Model : Made in Taiwan $530 \times 1100$

Series no : 12521

Variabel bebasanya kedalaman potong dengan kecepatan putar

Kedalaman potong $\quad: 0,4 \mathrm{~mm}$ dan $0,8 \mathrm{~mm}$ Kecepatan putar : $330 \mathrm{rpm}$ dan 490 rpm

varians data hasil kekasaran permukaan pada masing-masing kelompok. Deksripsi data kekasaran permukaan masing-masing kelompok dengan menggunakan program SPSS 20.0 for Windows disajikan pada tabel 1

Tabel 1 Deskripsi Data Hasil Kekasaran Permukaan Masing-Masing Kelompok

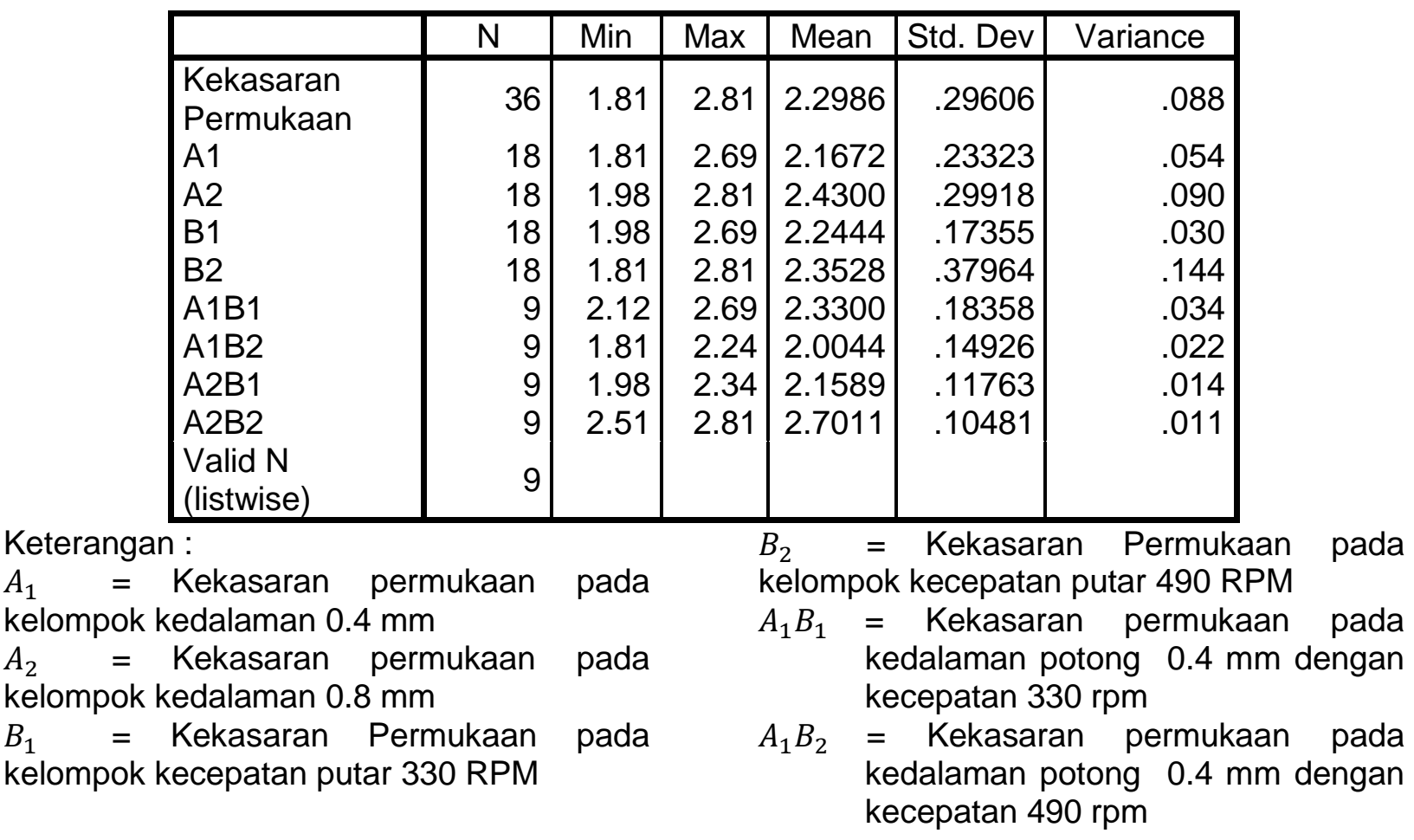


$A_{2} B_{1}=$ Kekasaran permukaan pada kedalaman potong $0.8 \mathrm{~mm}$ dengan kecepatan $330 \mathrm{rpm}$

\section{UJI NORMALITAS SEBARAN DATA}

Uji normalitas dilakukan pada hasil kekasaran permukaan. Uji normalitas ini dilakukan dengan menggunakan statistik
$A_{2} B_{1}=$ Kekasaran permukaan pada kedalaman potong $0.8 \mathrm{~mm}$ dengan kecepatan $330 \mathrm{rpm}$

Kolmogorov-Smirnov. Hasil uji normalitas data hasil kekasaran permukaan yang dimaksud dapat dilihat pada tabel 2

Tabel 2 Uji Normalitas Kekasaran Permukaan

\begin{tabular}{|c|c|c|c|c|c|c|}
\hline \multirow{2}{*}{} & \multicolumn{3}{|c|}{ Kolmogorov-Smirnov $^{\mathrm{a}}$} & \multicolumn{3}{c|}{ Shapiro-Wilk } \\
\cline { 2 - 7 } & Statistic & $\mathrm{df}$ & Sig. & Statistic & $\mathrm{df}$ & Sig. \\
\hline A1B1 & .129 & 9 & $.200^{*}$ & .939 & 9 & .566 \\
\hline A1B2 & .236 & 9 & .158 & .900 & 9 & .252 \\
\hline A2B1 & .181 & 9 & $.200^{*}$ & .957 & 9 & .767 \\
\hline A2B2 & .200 & 9 & $.200^{*}$ & .898 & 9 & .240 \\
\hline A1 & .125 & 18 & $.200^{*}$ & .972 & 18 & .837 \\
\hline A2 & .165 & 18 & $.200^{*}$ & .907 & 18 & .077 \\
\hline B1 & .134 & 18 & $.200^{*}$ & .975 & 18 & .882 \\
\hline B2 & .199 & 18 & .059 & .861 & 18 & .013 \\
\hline
\end{tabular}

Berdasarkan hasil uji normalitas sebaran data pada tabel 2 menunjukan bahwa nilai statistik Kolmogorov-Smirnov pada kekasaran permukaan nilai sig keseluruhan diatas 0.05 . Hasil ini menunjukan harga signifikasi pada kekasaran permukaan lebih besar 0.05 dengan mengunakan taraf signifikansi $5 \%$, sehingga data hasil penelitian dinyatakan normal.

\section{UJI HOMOGENITAS VARIANS}

Uji homogenitas varian antar kelompok dilakukan menggunakan SPSS 20.0. Hasil uji homogenitas varian data hasil kekasaran permukaan ditunjukan pada tabel

.Tabel 3 Hasil Kekasaran Permukaan Uji Homogenitas

\begin{tabular}{|l|l|r|r|r|r|}
\hline \multicolumn{2}{|c|}{} & $\begin{array}{c}\text { Levene } \\
\text { Statistic }\end{array}$ & df1 & df2 & Sig. \\
\hline $\begin{array}{l}\text { Kekasaran } \\
\text { Permukaan }\end{array}$ & Based on Mean & 3.892 & 1 & 34 & .057 \\
\cline { 2 - 6 } & Based on Median & 3.502 & 1 & 34 & .070 \\
\cline { 2 - 6 } & $\begin{array}{l}\text { Based on Median } \\
\text { and with adjusted df }\end{array}$ & 3.502 & 1 & $\begin{array}{r}33.93 \\
9\end{array}$ & .070 \\
\cline { 2 - 6 } & $\begin{array}{l}\text { Based on trimmed } \\
\text { mean }\end{array}$ & 3.733 & 1 & 34 & .062 \\
\hline
\end{tabular}

Berdasarkan tabel 3 hasil uji homogenitas kekasarn permukaan, nilai signifikansi pada kolom Based on Mean menunjukan harga sebesar 0,057. Hasil ini menunjukan harga signifikansi tersebut lebih besar dari 0,05 menggunakan taraf signifikansi $5 \%$ sehingga data hasil penelitian dinyatakan homogen.

\section{UJI ANAVA DUA JALUR}

Hasil uji hipotesis 1 (anava dua jalur) dengan menggunakan program SPSS 
20.0 for windows sekaligus hasil uji hipotesis 2 dan 3. Data hasil uji anava dua

jalur dapat dilithat pada tabel 4

Tabel 4 Uji anava Dua Jalur Kekasaran Permukaan

\begin{tabular}{|c|c|c|c|c|c|}
\hline Source & $\begin{array}{l}\text { Type III } \\
\text { Sum of } \\
\text { Squares }\end{array}$ & $\mathrm{df}$ & $\begin{array}{l}\text { Mean } \\
\text { Square }\end{array}$ & $\mathrm{F}$ & Sig. \\
\hline Corrected Model & $2.421^{a}$ & 3 & .807 & 34.885 & .000 \\
\hline Intercept & 190.210 & 1 & 190.210 & $\begin{array}{r}8220.8 \\
5\end{array}$ & .000 \\
\hline $\begin{array}{l}\text { Kedalaman } \\
\text { potong }\end{array}$ & .621 & 1 & .621 & 26.860 & .000 \\
\hline Kecepatan putar & .106 & 1 & .106 & 4.565 & .040 \\
\hline $\begin{array}{l}\text { Kedalaman } \\
\text { potong } \\
\text { kecepatan putar }\end{array}$ & 1.694 & 1 & 1.694 & 73.229 & .000 \\
\hline Error & .740 & 32 & .023 & & \\
\hline Total & 193.372 & 36 & & & \\
\hline Corrected Total & 3.162 & 35 & & & \\
\hline
\end{tabular}

Berdasarkan hasil analis pada tabel 4 dapat disimpulkan sebagai berikut

1. Pada kolom kedalaman potong besar nilai $F$ sebesar 26.860. Hasil ini menunjukan besar nilai $F$ lebih besar dari 4.11 ( $\mathrm{F}>$ 4.11). sehingga hasilnya adalah signifikan ( terdapat perbedaan yang signifikan)

2. Pada kolom kecepatan putar besar nilai $F$ sebesar 4.565. Hasil ini menunjukan besar nilai $F$ lebih besar dari $4.11(F>4.11)$. sehingga hasilnya adalah signifikan ( terdapat perbedaan yang signifikan)

Pada kolom kedalaman potong dan kecepatan putar besar nilai $F$ sebesar 73.229. Hasil ini menunjukan besar nilai $F$ lebih besar dari 4.11 ( $F>4.11$ ). Sehingga hasilnya adalah signifikan (ada interaksi yang signifikan)

\section{PEMBAHASAN HASIL PENELITIAN}

Pengujian ketujuh yang diajukan pada penelitian ini telah menghasilkan rangkuman hasil uji hipotesis sebagai berikut.

Hipotesis pertama, hasil hipotesis pertama telah berhasil menerima $H_{1}$ yang menyatakan bahwa ada perbedaan kekasaran permukaan antara kedalaman potong $0,4 \mathrm{~mm}$ dan kedalaman potong 0,8 $\mathrm{mm}$ pada bahan baja st 37 dibuktikan dengan nilai $F$ hitung $=26,860$ lebih besar dari $\mathrm{F}$ tabel $=4,11\left(\left(\mathrm{~F}_{\mathrm{h}}>\mathrm{F}_{\mathrm{t}}\right)\right.$

Hipotesis kedua, hasil uji hipotesis kedua telah berhasil menerima $H_{1}$ yang menyatakan bahwa ada perbedaan kekasaran permukaan antara kecepatan putar 330 rpm dan kecepatan putar 490 rpm pada bahan baja st 37 dibuktikan dengan nilai $F$ hitung $=4,565$ lebih besar dari $F$ tabel $=4,11\left(F_{h}>F_{t}\right)$

Hipotesis ketiga, hasil uji hipotesis ketiga berhasil menerima $H_{1}$ yang menyatakan bahwa terdapat interaksi antara kedalaman potong dan kecepatan putar terhadap kekasaran permukaan pada bahan baja st 37 dibuktikan dengan nilai $F$ hitung $=73,229$ lebih besar dari $\mathrm{F}$ tabel $=$ $4,11\left(\mathrm{~F}_{\mathrm{h}}>\mathrm{F}_{\mathrm{t}}\right)$

Hipotesis keempat, hasil uji hipotesis keempat berhasil menerima $H_{1}$ yang menyatakan bahwa pada kelompok kedalaman potong $0,4 \mathrm{~mm}$, terdapat perbedaan kekasaran antara kecepatan putar $330 \mathrm{rpm}$ dan kecepatan $490 \mathrm{rpm}$ pada bahan st 37 dibuktikan dengan nilai $Q$ 
hitung = 14 lebih besar dari $Q$ tabel $=2$, ( $\left.Q_{h}>Q_{t}\right)$

Hipotesis kelima, hasil uji hipotesis kelima menerima $H_{1}$ yang menyatakan bahwa pada kelompok kedalaman potong $0,8 \mathrm{~mm}$, terdapat perbedaan kekasaran antara kecepatan putar $330 \mathrm{rpm}$ dan kecepatan $490 \mathrm{rpm}$ pada bahan st 37 dibuktikan dengan nilai $Q$ hitung $=3,44$ lebih besar dari $\mathrm{Q}$ tabel $=2,875\left(\mathrm{Q}_{\mathrm{h}}>\mathrm{Q}_{\mathrm{t}}\right)$

Hipotesis keenam, hasil uji hipotesis keenam berhasil menerima $H_{1}$ yang menatakan bahwa pada kelompok 330 rpm, terdapat perbedaan kekasaran permukaan

\section{SIMPULAN}

Bedasarkan hasil penelitian dan pembahasan diatas, dapat disimpulkan

1. Terdapat perbedaan kekasaran permukaan antara kedalaman potong $0,4 \mathrm{~mm}$ dan kedalaman potong $0,8 \mathrm{~mm}$ pada bahan baja st 37 dibuktikan dengan nilai $F$ hitung $=26,860$ lebih besar dari $\mathrm{F}$ tabel $=4,11\left(\mathrm{~F}_{\mathrm{h}}>\mathrm{F}_{\mathrm{t}}\right)$

2. Terdapat perbedaan kekasaran permukaan antara kecepatan putar 330 rpm dan kecepatan putar 490 rpm pada bahan baja st 37 dibuktikan dengan nilai $F$ hitung $=4,565$ lebih besar dari $F$ tabel $=4,11\left(F_{h}>F_{t}\right)$

3. Terdapat terdapat interaksi antara kedalaman potong dan kecepatan putar terhadap kekasaran permukaan pada bahan baja st 37 dibuktikan dengan nilai $F$ hitung $=73,229$ lebih besar dari $\mathrm{F}$ tabel $=4,11\left(\mathrm{~F}_{\mathrm{h}}\right.$ $>\mathrm{F}_{\mathrm{t}}$ )

4. Pada kelompok kedalaman potong 0,4 $\mathrm{mm}$, terdapat perbedaan kekasaran antara kecepatan putar $330 \mathrm{rpm}$ dan kecepatan $490 \mathrm{rpm}$ pada bahan st 37 dibuktikan dengan nilai $Q$ hitung $=14$ lebih besar dari $Q$ tabel $=2,875\left(Q_{\mathrm{h}}>\mathrm{Q}_{\mathrm{t}}\right)$

5. Pada kelompok kedalaman potong $0,8 \mathrm{~mm}$, terdapat antara kedalaman potong $0,4 \mathrm{~mm}$ dan kedalaman potong $0,8 \mathrm{~mm}$ pada bahan baja st 37 dibuktikan dengan nilai $Q$ hitung $=6,6$ lebih besar dari $\mathrm{Q}$ tabel $=2,875\left(\mathrm{Q}_{\mathrm{h}}>\right.$ $\left.Q_{t}\right)$

Hipotesis ketujuh, hasil uji hipotesis ketujuh berhasil menerima $H_{1}$ yang menatakan bahwa pada kelompok 490 rpm, terdapat perbedaan kekasaran permukaan antara kedalaman potong $0,4 \mathrm{~mm}$ dan kedalaman potong $0,8 \mathrm{~mm}$ pada bahan baja st 37 dibuktikan dengan nilai $Q$ hitung $=10,84$ lebih besar dari $Q$ tabel $=2,875$ ( $\left.\mathrm{Q}_{\mathrm{h}}>\mathrm{Q}_{\mathrm{t}}\right)$

perbedaan kekasaran antara kecepatan putar $330 \mathrm{rpm}$ dan kecepatan $490 \mathrm{rpm}$ pada bahan st 37 dibuktikan dengan nilai $Q$ hitung $=3,44$ lebih besar dari $Q$ tabel $=2,875\left(Q_{h}>Q_{t}\right)$

6. Pada kelompok $330 \mathrm{rpm}$, terdapat perbedaan kekasaran permukaan antara kedalaman potong $0,4 \mathrm{~mm}$ dan kedalaman potong $0,8 \mathrm{~mm}$ pada bahan baja st 37 dibuktikan dengan nilai $Q$ hitung $=6,6$ lebih besar dari $Q$ tabel $=2,875\left(Q_{h}>Q_{t}\right)$

7. Pada kelompok $490 \mathrm{rpm}$, terdapat perbedaan kekasaran permukaan antara kedalaman potong $0,4 \mathrm{~mm}$ dan kedalaman potong $0,8 \mathrm{~mm}$ pada bahan baja st 37 dibuktikan dengan nilai $Q$ hitung $=10,84$ lebih besar dari $Q$ tabel $=2,875\left(Q_{h}\right.$ $>Q_{t}$ )

\section{SARAN}

Berdasarkan hasil penelitian ini disarankan untuk meningkatkan hasil kehalusan permukaan pada bahan st 37 dengan diameter $21 \mathrm{~mm}$ maka kedalaman potong yang digunakan adalah $0,4 \mathrm{~mm}$ dengan kecepatan putar 490 rpm.

\section{DAFTAR PUSTAKA}

Agung, Anak Agung Gede. 2015. Statistik Inferensial. Singaraja: Fakultas IImu Pendidikan

Asmed dan Yusri Mura, 2010. Pengaruh Parameter Pemotongan Terhadap 
Kekasaran Permukaan Proses Bubut Untuk Material ST 37. Jurnal. Staf Pengajar Jurusan Teknik Mesin, Politeknik Negeri Padang

Azhar, M. C. 2014. Analisa Kekasaran Permukaan Benda Kerja dengan Variasi Jenis Material dan Pahat Potong. Skripsi. Bengkulu: Universitas Bengkulu.

Ahmad cholid, 2013.“ Belajar Teknik Pemesinan". Tersedia pada http://ahmadcholid smkn35jakbar.blogspot.co.id/2013/01/rumusperhitungan-mesin-bubut.html (diakses tanggal 28)

Bimbing Atedi dan Djoko Agustono. 2005. Pengaruh Kekasaran Terhadap Proses Pembubutan. Tersedia pada http: //mashaqi10.blogspot.com. html ( tanggal 1)

Kristo Am 2014 "Parameter dan perhitungan kecepatan pisau frais metric parameter and calculation speed metric of milling cutter". Tersedia pada http://machiningtool.blogspot.co.id/20 14/10/parameter-dan-perhitungankecepatan.html (diakses tanggal 2)

Child, dkk. 2000. Metal Machining Theory and Aplication. New York: Jonh Wiley \& Sons Inc.

Hadimi, 2008. Pengaruh Perubahan Kecepatan Pemakanan Terhadap Kekasaran Permukaan Pada Proses Pembubutan. Jurnal. Jurusan Teknik Mesin, Politeknik Negeri Pontianak.

Hoiri Efendi 2014 "Bagian - bagian utama mesin bubut". Tersedia pada http://arudamkanateknik.blogspot.co.i d/2014/07/bagian-bagian-utamamesin-bubut.html (diakses tanggal 2) Ishikawa, Kaoru. 1992. Pengendalian Mutu Terpadu. Diterjemahkan oleh Budi Santoso. Bandung: Remaja Rosdakarya.

Koyan, Wayan. 2012.Statistik Pendidikan Teknik Analisi Data Kuantitatif, Edisi 1, Cetakan Pertama.Singaraja: Universitas Pendidikan Ganesha.

Kalpakjian. 2001. "Pengaruh Kekasaran Terhadap Proses Pembubutan". Tersedia pada http: //mashaqi10.blogspot.com. html tanggal 1)

Kamil toha 2014 " Jenis-jenis pahat pada mesin bubut". Tersedia pada http://kamiltoh4.blogspot.co.id/ (diakses tanggal 28)

Munadi, S., 1988. Dasar-dasar Metrologi Industri. Jakarta: DIKTI

Rochim, T. 1993. Proses Pemesinan. Bandung: HEDSP.

Susarno, Ardiyan. 2012 Pengaruh Sudut Potong Pahat HSS Pada Proses Bubut Dengan Tipe Pemotongan Orthogonal Terhadap Kekasaran Permukaan. Skripsi. Jurusan Teknik Mesin Fakultas Teknik, Universitas Muhamadiyah Surakarta

Widiarto, 2008.Teknik Pemesinan Jilid 1 Untuk SMK. Jakarta: Direktorat Pembinaan Sekolah Menengah Kejuruan, Direktorat Jenderal Manajemen Pendidikan Dasar dan Menengah, Departemen Pendidikan Nasional. 